\title{
Migration Discourse Structures: Escaping Microsoft's Desktop Path
}

\author{
Leonhard Dobusch \\ Free University Berlin - School for Business \& Economics, \\ Garystr. 21, 14195 Berlin, \\ leonhard.dobusch@wiwiss.fu-berlin.de \\ WWW home page: http://www.pfadkolleg.de
}

\begin{abstract}
Most studies of FOSS organizational migration projects focus solely on technological and economical aspects, neglecting the importance of organizational discourse structures for migration decisions as well as success. In looking at the case of the municipality of Munich this paper uses structuration theory in combination with discourse analysis to explain why and how in this case actors were able to overcome strong barriers to migration in the field of desktop software.
\end{abstract}

Keywords: Open Source Software; Path Dependency; Technology Adoption; Structuration Theory; Discourse Analysis

\section{Introduction}

Of all recent examples of organizations switching their software environment to Free/Open Source Software (FOSS) the municipality of Munich in Germany received significant attention, at least in the media. The reasons for this are the following:

- Munich decided to migrate the whole desktop software environment including operating system and office suite to FOSS - not only server software or office suits as had done many organizations before.

- With approximately 14.000 desktops the municipality in Munich is by far larger than other municipal predecessors such as for example Schwäbisch-Hall with about 225 desktop PCs [19].

- Only few weeks before the migration decision in May 2003 Microsoft's CEO Steven Ballmer met with Munich's mayor Ude to convince him not to do so and failed.

But aside these aspects the migration decision and process in Munich is also a critical case [34] for studying why and how organizations take the lead in adopting a minority system in markets with strong network effects, often referred to as "path 
dependent" $[6,3]^{1}$. Whereas many studies of FOSS adoption, especially in the domain of information systems, focus on technical implementation and migration issues (e.g. [22]) and do not distinguish between desktop and server usage (e.g. [1]), the organizational processes associated with these migrations are often overlooked or underrated.

In combining structuration theory $[12,20,21,24]$ with concepts of discourse analysis $[14,4,5]$ this paper tries to conceptualize why and how organizations take the lead in escaping Microsoft's desktop software path.

\section{FOSS Adoption as a Case of Path Breaking}

\subsection{Path dependency in software markets}

Following Shapiro and Varian [23] as well as Varian et al. [29] there are several mechanisms in software markets such as network effects, investment and learning spirals or complementarity (see Table 1) that differentiate them from "classic markets". All these mechanisms are recursively self-reinforcing and thus increase switching costs of individual adopters over time, making a migration to FOSS an expensive and laborious task. Following David's [6,7] notion of path dependency, Microsoft's monopoly position in the market for desktop operating systems and office suites doesn't prevail because of the superiority of its products but because of their customer's lock-in on them.

Table 1. Selection of mechanisms leading to switching costs in desktop software markets

\begin{tabular}{ll}
\hline Mechanism & Example \\
\hline Direct and indirect network effects & $\begin{array}{l}\text { The larger the installed base of a piece of software, the } \\
\text { greater the benefits (also for the individual actor) of adopting } \\
\text { it. [10] }\end{array}$ \\
\hline Investment and learning spirals & $\begin{array}{l}\text { Investments into a specific piece of software lead to even } \\
\text { more investments into the same, creating a growing stock of } \\
\text { idiosyncratic assets. [33] }\end{array}$ \\
\hline Complementarity & $\begin{array}{l}\text { Two (or more) in principle autonomous mechanisms - e.g. } \\
\text { software diversity and organizational decentralization - } \\
\text { reinforce one another. [26] }\end{array}$ \\
\hline
\end{tabular}

However, the logic that leads to path dependency of (in particular: organizational) actors in software markets results from mutual and recursive interdependencies between technological and social structures. Orlikowski [20, 21] calls this the "duality of technology":

1 Shapiro and Varian [23] even call the market for desktop software „everyone's favourite example" for concepts like "lock-in" or "increasing returns". 
The duality of technology identifies prior views of technology - as either objective force or as socially constructed product - as a false dichotomy. Technology is the product of human action, while it also assumes structural properties. That is, technology is physically constructed by actors working in a given social context, and technology is socially constructed by actors through the different meanings they attach to it and the various features they emphasize and use. [20:496]

In an organizational context the mechanisms described in Table 1 do not effect software adoption directly but are mediated through intra-organizational dynamics and structures. Stones' [24] "quadripartite" notion of structuration [12] was originally developed for the individual actor but seems to be applicable on the organizational level, as well (see Figure 1). The main point of structuration theory is to ac-knowledge the "duality at work in which agents and structures are not kept apart but in which they are mutually constitutive of one another" [24:21].

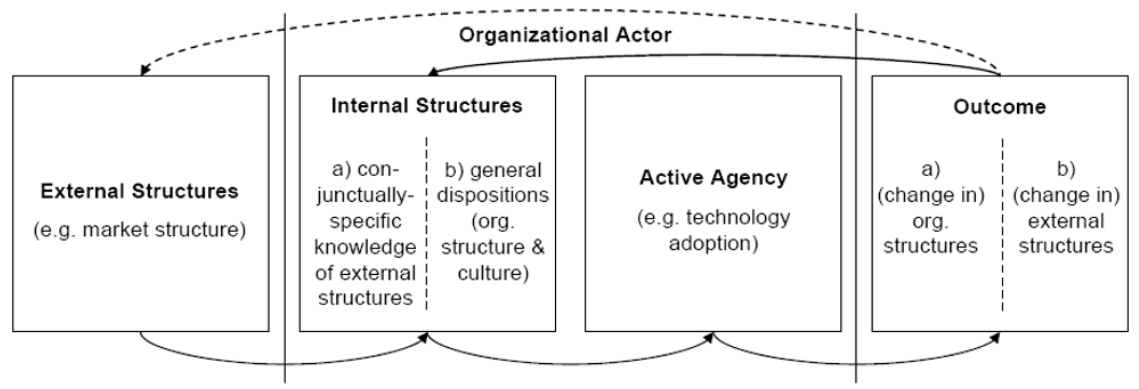

Fig. 1. Structuration model of technology adoption

\subsection{Path breaking FOSS?}

The reasons why there is still competition in the market for desktop PC operating systems lie in the idiosyncratic characteristics of recently developed FOSS alternatives such as GNU/Linux which differ in development process [31], license fees, access to source code, and strong competition among several suppliers in a way that is impossible to imitate for Microsoft if it wants to prolong its business model. ${ }^{2}$ Nevertheless, the barriers to migration especially in the market for desktop operating systems - contrary to the server market - still seem to prevent Microsoft from serious competition in this field [13]. Especially large organizations hesitate to

2 For an overview of the differences between Free/Open Source and proprietary software, see the anthology by [11]. 
switch their desktop software environment to alternatives provided by open source software competitors ([32], see Table 2), and still little is known why and how they do so.

Table 2. FOSS desktop usage in organizations in three countries (taken from Wichmann [32])

\begin{tabular}{llll}
\hline Size* & UK & Sweden & Germany \\
\hline Small & $7,6 \%$ & $3,4 \%$ & $13,7 \%$ \\
Large & $2,0 \%$ & $3,2 \%$ & $6,5 \%$ \\
\hline$* 500$ employees $=$ small $>500$ employees $=$ large & & & \\
\hline
\end{tabular}

What we do know, however, is that technological and economic reasons may not play a decisive role in the question whether to adopt FOSS or stay on the Microsoft path, as Varian and Shapiro ([30:12]; italics by L.D.) summarize their review of TCO comparisons in the literature:

There have been several attempts to compare the TCO of Windows and of Linux in various computing environments. In most of the studies the difference in TCO is on the order of 10 or 15 percent. This difference is not large; a 10 percent difference in TCO could easily be swamped by local conditions, random events, and other considerations. To a first approximation, it seems reasonable to suppose that neither of these two platforms has a striking advantage over the other in terms of conventional measures of TCO.

So the question remains why and how do organizations then decide to migrate their desktop software environment to FOSS alternatives in spite of strong network effects? This paper suggests taking a look at the organizational migration discourse.

\section{Method Section}

\subsection{Data collection}

Following Yin [34:8], the unique strength of a case study is "its ability to deal with a full variety of evidence", including documents, artifacts, interviews, and observations. To live up to this potential and for triangulation reasons, over a two year period from 2006 to 2007 data was collected in form of open-ended interviews with actors on different organisational levels, transcripts of talks given at practitioner conferences, archival documents including the "Client Study" of Unilog Integrata (consulting firm, [28]) and media coverage. All data was integrated into a case study database (see Table 3 ) but only transcripts were included in the discourse analysis. 
Table 3. Case Study database

\begin{tabular}{ll}
\hline transcripts & \\
\hline interviews / persons & $7 / 7$ \\
talks / persons & $3 / 3$ \\
$\begin{array}{l}\sum \text { transcripts / persons } \\
\text { per functional area (transcripts / persons): }\end{array}$ & $2 / 2$ \\
\hline political administration & $5 / 3$ \\
central IT & $2 / 2$ \\
decentral IT & $2 / 2$ \\
\hline external* & $68 / 34$ \\
media coverage (2001-2007)** & 11 \\
articles (online / print) & 31 \\
archival documents & 7 \\
sets of slides & \\
agenda papers & \\
miscellaneous & \\
* “external” includes service provider and consultants \\
** articles from the following sources from 2002-2007: \\
$\begin{array}{l}\text { Heise.de, Computerwoche, Frankfurter Allgemeine } \\
\text { Zeitung, Frankfurter Rundschau, Süddeutsche Zeitung }\end{array}$ \\
\hline
\end{tabular}

\subsection{Discourse analysis}

In adopting the cyclical ideal of qualitative research [25], the data analysis was divided into three parts that were not undertaken in strict consecutiveness: Inductive generation of theoretical categories of both mechanisms enforcing and weakening path dependency is complemented with chronological process descriptions. These two parts are connected in a final theoretical integration, using archival documents and media coverage to cross-check interview data and for the right temporal ordering.

For categorization, the literally transcribed interviews and talks were reduced to 692 paraphrases as the basis for coding the data. Then, in multiple, consecutive rounds a system of coding categories was developed with focus on the meta-category "barriers and drivers for the adoption of an alternative (i.e. non-Microsoft) desktop operating system" $[16,18]$. These inductively generated categories were then classified as predominantly covering "Framing" or "Program" aspects of the migration discourse - a dichotomy taken from Campbell's [4, 5:94] typology of ideas, which differentiates between the two as follows:

- Programs are "ideas as elite prescriptions that enable [...] the charting of a clear and specific course of action"

- Frames are "ideas as symbols and concepts that enable decision makers to legitimise programs to their constituents". 
In integrating these categories in an organizational structuration model as it is presented in Figure 2, the translation of discourse into organizational technology adoption can be conceptualized.

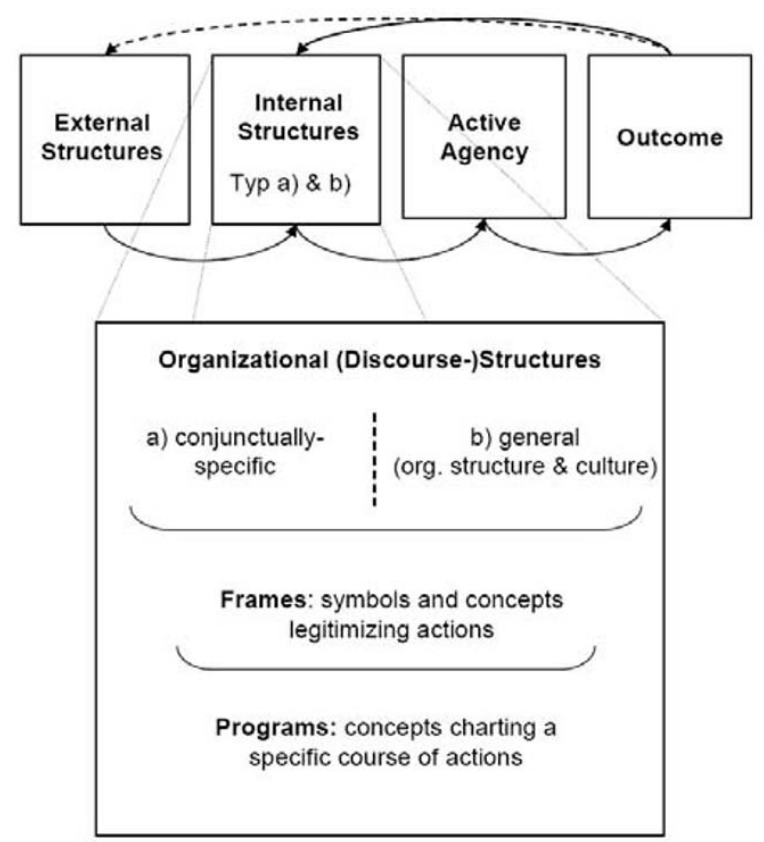

Fig. 2. Organizational discourse structures

\section{Munich's Migration Process and Discourse}

The following description of the FOSS migration process in Munich is a radically condensed version of a much more detailed narration provided in [8].

\subsection{The process: emergence of radical change}

One core concept of path dependency theory in a narrow sense ${ }^{3}$ is that of "small events": A series of small, partially unrelated or even stochastic events sets in motion a self-reinforcing process that eventually leads from a contingent state at the

3 "Narrow" is meant in the tradition of David [6] and Arthur [3] and compared to scholars using "path" and "path dependency" only as a metaphor for the truism that "history matters". For an extensive discussion, see Dobusch and Schüßler [9]. 
beginning to a state of ex-ante unpredictable lock-in [7, 26,].The case of Munich demonstrates that small events can also play a decisive role in the early stages of a path breaking process.

The politician - a private user of the proprietary "Ami Pro" - who set the ball rolling by suggesting the search for alternatives to Microsoft (MS) Office was only a backbencher ("Hinterbänkler") in the city council, which he left soon after his motion. The first reaction of the IT officials was an attempt to turn the whole issue done by a simple product comparison between MS Office and several alternatives (see Table 4).

Table 4. Product comparison prepared by the central IT department for the responsible council committee's meeting in Nov. 2001

\begin{tabular}{ll}
\hline Advantages & Disadvantages \\
\hline StarOffice is Open Source Software & Re-working in existing documents necessary because of \\
Lower purchase costs & - partial lack of import/export \\
End of dependence on Microsoft & - different macro languages \\
Cross platform applicability & - different object models \\
(StarOffice) & New product line needs requires more training and, \\
therefore, leads to higher training costs & There is no in-house training personnel \\
& Insufficent online-help (StarOffice) \\
& StarOffice/SmartSuite data formats are mostly not \\
suitable for data exchange. Documents would have to be & handed on in MS Office or RTF format. \\
The already deployed - and paid for - MS Office \\
products would have to be replaced all over although \\
they are often not even amortised (to ensure readability in \\
internal data exchange) \\
No mail-client (SmartSuite)
\end{tabular}

Dissatisfied with their IT official's analysis, the political members of the committee demanded a second, more in-depth evaluation with special focus on economic efficiency, also taking into consideration the desktop operating system, as Microsoft had already cancelled its support for the Windows version in use. The following expert's advice [28] then convinced the IT staff of the viability of a FOSS solution. When this result was presented to the council committee, the situation surprisingly was the opposite way round compared to autumn 2001, as one of the officials describes:

"When, for the first time, we proposed Linux on the basis of the external study in autumn 2002 in the IT committee [...] we got a lot of stick ((laughs)) [...] and I thought we don't even need to continue, we slunk off with our tails between our legs."

At the same time, the results of the "Client Study" and its recommendation to migrate alerted Microsoft - up to the CEO level: In April 2003, Microsoft CEO Steven 
Ballmer interrupted his holidays in Switzerland to visit Munich's mayor. But, again, an attempt to turn down the migration plan even strengthened the momentum behind it: The amount of media coverage skyrocketed, thus increasing pressure on politicians to resist to the monopolist's power. As another consequence of the increased public interest, many firms and other municipalities encouraged Munich's officials and politicians to stay on their way and offered knowledge exchange. Additionally, Microsoft's move also motivated its competitors IBM and NovellSuse to upgrade their offers of assistance during a potential migration process. In May 2003, after weeks of heated seesaw changes in the calculation of the different alternatives, the council made the principle decision in favour of a migration to FOSS and authorised its IT department to work out a detailed draft for the project.

Consciousness of the actual costs, complexity and efforts connected with this decision only rose incrementally along the following migration process. What had started as a search for an alternative office software suite in 2001 had ended as a complete restructuring of the municipality's IT organization and processes:

- After the migration, only one standardized and centrally developed operating system version replaced the several different Windows versions.

- As a consequence of the standardized client, many prior decentralised tasks and routines (e.g. operating system set up ${ }^{4}$, administration and configuration) were going to be fulfilled by a central client team.

- In introducing a new standardized tool to manage office forms and master documents called "Wollmux", the city's corporate design guidelines were to be reinforced and - for the first time in history - to be implemented uniformly in the whole municipality.

- The change of the operating system gave reason for a general consolidation of the municipality's diverse software landscape, reducing the variety of applications in use.

Summing up this short description, there are at least three remarkable aspects of Munich's odyssey from Windows to FOSS (see also Figure 3): First, technology adoption and organisational change - especially concerning different degrees of organisational (de)centrality - are deeply intertwined and reciprocally enforcing. Second, roles and preferences of individual actors change during the process, converting some of them from opponents into proponents and vice-versa. It is, therefore, impossible - or at least, misleading - to simply reduce individual attitudes towards the adoption of Free and Open Source Software to their job functions as it is tried by Alexy and Henkel [1], and underlines the importance of applying a process perspective in researching adoption decisions. Third, external advice and

4 Although all departments had adopted the same operating system (Windows NT), its set up in terms of administration tools, settings, and support software varied.

5 "Wollmux" is a neologism combining the German "eierlegende Wollmilchsau" (colloquial for "all-in-one device suitable for every purpose") and the name of the Linux mascot "Tux". 
interventions play an important catalytic role in the process, but at the same time are only "perturbations" [17] of overall internal organizational dynamics.

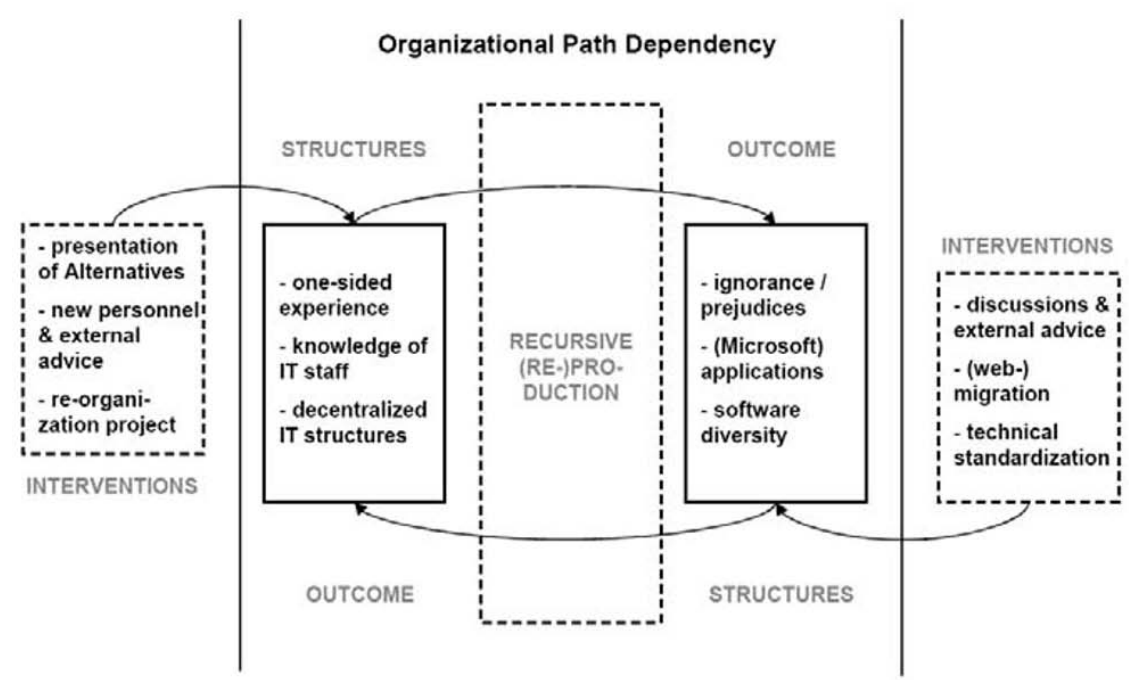

Fig. 3. Recursive re-production of organizational software paths and respective interventions

\subsection{The discourse: coalitions of actors and issues}

Table 5 depicts relative frequencies of dominant issues raised by actors in different organizational subsystems - political administration, central and decentral IT departments - on the basis of inductively generated coding categories [18]. It distinguishes thereby between legitimizing frames and programs charting a specific course of action $[4,5]$ both of which were - depending on the respective context predominantly coded as either pro- or anti-migration ${ }^{6}$.

In Munich, two different organizational camps applied different frames to legitimize the same FOSS migration project and thus build what Hajer [14] calls a "discourse coalition". On the one hand, politicians stressed frames referring to a diffuse "anti-monopoly" ideology and the particular responsibility as a public administration. The central IT officials, on the other hand, framed the introduction of FOSS above all as the (looked-for) opportunity to re-centralize the municipality's organizational IT structure; for them - as the only subgroup - switching gains exceed switching efforts. Together, these two camps generate enough momentum [15] to

${ }^{6}$ Except for some unidimensional coding categories, most categories aggregate two antithetic codes that cover statements referring either to barriers and downsides or drivers and advantages of a migration to FOSS. A category was classified as "predominantly pro- or anti-migration" if there was a difference larger than unity between the two. 
overcome the strong innovation barriers of the desktop software markets. Together, these two camps generate enough momentum to overcome the strong barriers to FOSS introduction that materialized also in resistance in decentralized IT departments. Those opposed the migration as their expert's knowledge - gained over years of "learning by doing" [2] - depreciated rapidly under a new operating system because of the „creative destruction“ of skills and knowledge in every technological innovation process [27].

Table 5. Dominant Frames and Programs in Munich's Migration Discourse

\begin{tabular}{|c|c|c|}
\hline & $\begin{array}{l}\text { Frames } \\
\text { (Top } 3 \text { out of } 15 \text { categories with a total } \\
\text { of } 439 \text { codings) }\end{array}$ & $\begin{array}{l}\text { Programs } \\
\text { (Top } 3 \text { out of } 12 \text { categories with a total } \\
\text { of } 486 \text { codings) }\end{array}$ \\
\hline $\begin{array}{l}\text { Political } \\
\text { administration }\end{array}$ & $\begin{array}{l}18,68 \% \text { anti-monopoly }\left(^{* * *}\right) \\
17,58 \% \text { (overall) profitability } \\
14,29 \% \text { public administration issues }\end{array}$ & $\begin{array}{l}27,14 \% \text { discussions } \\
15,71 \% \text { external advice } \\
12,86 \% \text { migration complexity }\left({ }^{\star}\right)\end{array}$ \\
\hline $\begin{array}{l}\text { Central IT } \\
\text { department }\end{array}$ & $\begin{array}{l}25,98 \% \text { switching gains \& efforts } \\
18,63 \% \text { organisational structures }\left(^{*}\right) \\
15,20 \% \text { (overall) profitability }\end{array}$ & $\begin{array}{l}27,52 \% \text { migration strategy } \\
24,03 \% \text { applications (incl. } \\
\text { macros) }\left(^{* *}\right) \\
9,30 \% \text { organisational know-how }\left(^{*}\right)\end{array}$ \\
\hline $\begin{array}{l}\text { Decentral IT } \\
\text { departments }\end{array}$ & $\begin{array}{l}26,39 \% \text { organisational structures }\left(^{*}\right) \\
\left.22,92 \% \text { switching gains \& efforts }{ }^{*}\right) \\
14,58 \% \text { expectations \& uncertainty }\end{array}$ & $\begin{array}{l}17,09 \% \text { organisational know-how }\left(^{*}\right) \\
16,46 \% \text { migration strategy } \\
15,19 \% \text { migration complexity }\left({ }^{*}\right)\end{array}$ \\
\hline$\left({ }^{* *}\right)$ unidimensi & $\begin{array}{l}\text { ntly coded anti-migration } \\
\text { ional anti-migration code } \\
\text { sional pro-migration code }\end{array}$ & \\
\hline
\end{tabular}

Looking at the categories that predominantly cover program aspects in the migration discourse (see right column in Table 5) one can see several facets more clearly: First, migration to FOSS is hard work and requires a lot of effort, in particular in cases of large-scale, rather complete migration projects like the one in Munich: Especially in both IT-departments categories that are predominantly coded anti-migration prevail and reflect the efforts necessary to migrate hundreds of special purpose applications and thousands of macros, forms and templates. Second, the program categories mirror the interventions depicted in Figure 3 and hence give an impression of the great variety of tasks necessary in such a migration project. Third, the again anti-migration position of the officials in the decentralized IT departments corresponds with the fact that they have to carry most of the migration burdens. Many of the migration tasks such as for example altering macros or forms means work, which at least in parts is additional to day-to-day routines.

Compared to other prominent and large-scale FOSS migration examples like the French car manufacturer PSA Peugeot ${ }^{7}$ or police forces in France and 
Niedersachsen/Germany ${ }^{8}$, Munich's migration enterprise is illuminative for at least two reasons: First, migration complexity and efforts seem to grow disproportionately if not only significant parts as in the case of PSA Peugeot but the complete software environment is to be changed in a rather short period of time. Second, migration complexity and efforts seem to grow disproportionately with functional and hence software diversity in an organization. As opposed to police force cases in France and Germany where only few special purpose applications have to be migrated and the functional diversity is relatively low, in large municipal administrations the situation is the other way round. This in turn led at least in Munich to the need for organizational re-structuring which complicated the migration process and viceversa.

\section{Conclusions}

Not only because of a municipality being a (at least: partially) political organization, the decision to (not) adopt FOSS in organizational contexts is always a political one: In organizations there will be winners and losers of migration processes as switching one's desktop software environment affects (complementary) organizational variables such as degree of decentralization or individual and organizational knowhow. As a consequence, future research of FOSS adoption processes should include both looking at the (changes in the) migration discourse and at its organizational contextualisation. This study can only be a first step into this direction.

\section{Acknowledgments}

I wish to thank Jörg Sydow, Sigrid Quack, Jochen Koch, Arndt Sorge and Elke Schüßler as well as all other members of the doctoral program "Research on Organizational Paths" at Freie Universitaet Berlin and the participants at the First Graz Schumpeter Summer School 2007 for their valuable comments.

\section{References}

[1] Alexy, O. and J. Henkel (2007). Promoting the Penguin: Who is Advocating Open Source Software in Commercial Settings? Working Paper. http://papers.ssrn.com/sol3/papers.cfm? abstract_id=988363. Accessed 16 October 2007.

[2] Arrow, K.J. (1962). The Economic Implications of Learning By Doing. The Review of Economic Studies, 29(3), 155-173

8 http://ec.europa.eu/idabc/en/document/7343/528, accessed 27 February 2008 and http://www.heise.de/newsticker/meldung/40374/ accessed 14 December 2008. 
[3] Arthur, B. (1989). Competing Technologies, Increasing Returns, and Lock-In by Historical Events. The Economic Journal, 99, 116-131

[4] Campbell, J.L. (1998). Institutional analysis and the role of ideas in the political economy. Theory and Society, 27, 377-409

[5] Campbell, J.L. (2004). Institutional Change and Globalization. Princeton: Princeton University Press.

[6] David, P.A. (1985). Clio and the economics of QWERTY. American Economic Review, 75 (2), 332-337

[7] David, P.A. (2000). Path Dependence, its critics and the quest for historical economics. Stanford Working Paper Series. http://www-econ.stanford.edu/faculty/workp/swp00011.pdf. Accessed 16 April 2007.

[8] Dobusch, L. (2007). Adopter Innovation in Network Markets: The Case of Linux in Munich. Paper presented at the SASE Annual Meeting, Kopenhagen 28-30 June 2007, Network on Knowledge, Technology and Innovation.

[9] Dobusch, L. and E.S. Schuessler (2007). From Storytelling to Theory: Unlocking Path Dependency from Metaphorical Usage. Paper presented at 23rd EGOS Colloquium, Vienna 5-7 July 2007, Sub-theme 14: Path dependencies and beyond.

[10] Farrell, J. and G. Saloner (1986). Installed Base and Compatibility: Innovation, Product Preannouncements, and Predation. The American Economic Review, 76 (5): 940-955

[11] Feller, J., B. Fitzgerald, S.A. Hissam, and E.R. Lakhani (Eds./2007). Perspectives on Free and Open Source Software. MIT Press. http://mitpress.mit.edu/books/chapters/0262562278. pdf. Accessed 28 March 2007.

[12] Giddens, A. (1984). The Constitution of Society: Outline of the Theory of Structuration. Cam-bridge: Polity Press.

[13] Gosh, R.A., B. Krieger, R. Glott and G. Robles (2002). Free/Libre and Open Source Software: Survey and Study. Part 2B: Open Source Software in the Public Sector: Policy within the European Union. International Institute of Infonomics, University of Maastricht. http://www.flossproject.org/report/FLOSSFinal_2b.pdf. Accessed 15 October 2007.

[14] Hajer, M.A. (1993). Discourse Coalitions and the Institutionalization of Practice: The Case of Acid Rain in Great Britain. In Fischer, F. and J. Forester (Eds.): The Argumentative Turn in Policy Analysis and Planning (pp. 43-76). Durham and London: Duke University Press.

[15] Hughes, T.P. (1983). Networks of Power: Electrification in Western Society 1880-1930. Baltimore: Johns Hopkins University Press.

[16] Mayring, P. (2003). Qualitative Inhaltsanalyse: Grundlagen und Techniken.: Weinheim and Basel: Beltz

[17] Maturana, H.R. and F.J. Varela (1987). The Tree of Knowledge: The Biological Roots of Human Understanding. Boston: Shambhala.

[18] Miles, M.B./Huberman, A.M. (1994). Qualitative Data Analysis: An expanded Sourcebook. Second Edition. Thousand Oaks: Sage

[19] Nagler, M. (2005). Migration of the German City of Schwäbisch Hall. http://ec.europa.eu/idabc/servlets/Doc?id=19734. Accessed 12 December 2007.

[20] Orlikowski, W.J. (1992). The Duality of Technology: Rethinking the Concept of Technology in Organizations. Organization Science, 3 (3), 398-427

[21] Orlikowski, W.J. (2000). Using Technology and Constituting Structures: A Practice Lens for Studying Technology in Organizations. Organization Science, 11 (4), 404-428

[22] Rossi, B., B. Russo and G. Succi, G. (2007). Open Source Software and Open Data Standards as a form of Technology Adoption: a Case Study. In Feller, J., B. Fitzgerald, W. 
Scacchi and A. Sillitti (Eds.): IFIP International Federation for Information Processing, Volume 234, Open Source Development, Adoption and Innovation, 325-330

[23] Shapiro, C. and H.R. Varian (1999). Information Rules: a strategic guide to the network economy. Cambridge (MA): Harvard Business School Press

[24] Stones, R. (2005). Structuration Theory. Houndmills et al.: Palgrave Macmillan:

[25] Strauss, A.L. and J. Corbin (1990). Basics of Qualitative Research: Grounded Theory Procedures and Techniques. Newbury Park (CA): Sage

[26] Sydow, J., G. Schreyögg, G. and J. Koch (2005). Organizational Paths: Path Dependency and Beyond. Paper presented at the 21st EGOS Colloquium, June 30 - July 2, 2005, Berlin, Germany

[27] Tushman, M.L. and P. Anderson (1986). Technological Discontinuities and Organizational En-vironments. Administrative Science Quarterly, 31, 439-465

[28] Unilog Integrata (2003). Client Studie der Landeshauptstadt München: Kurzfassung des Abschlussbereichts inklusive Nachtrag. Stand 02.07.2003. http://www.muenchen.de/limux. Accessed 26 February 2008.

[29] Varian, H.R., J. Farell, and C. Shapiro (2004). The Economics of Information Technology: An Introduction. Cambridge (UK): Cambridge University Press.

[30] Varian, Hal R. and Carl Shapiro (2003), Linux Adoption in the Public Sector: An Economic Analysis, http://www.sims.berkeley.edu/ hal/Papers/2004/linux-adoption-inthe-public-sector.pdf. Accessed 28 October 2005.

[31] von Hippel, E. and G. von Krogh (2003). Open Source Software and the „PrivateCollective“ Innovation Model: Issues for Organization Science. Organization Science,14(2), 209-223

[32] Wichmann, T. (2002). FLOSS Final Report - Part 1: Use of Open Source Software in Firms and Public Institutions - Evidence from Germany, Sweden and UK. Berlin: Berlecon Research.

[33] Williamson, O.F. (1985). The Economic Institutions of Capitalism. New York: The Free Press.

[34] Yin, R.K. (1994). Case Study Research. Design and Methods. Thousand Oaks: Sage. 